\title{
The Cup Anemometer, a Fundamental Meteorological Instrument for the Wind Energy Industry
}

\section{Santiago Pindado ${ }^{1,2}, *$, Javier Cubas ${ }^{1}$ and Félix Sorribes-Palmer ${ }^{1}$}

1 Instituto Universitario de Microgravedad "Ignacio Da Riva" (IDR/UPM), Universidad Politécnica de Madrid, ETSI Aeronáuticos, Pza. Del Cardenal Cisneros 3, Madrid 28040, Spain; E-Mails: santiago.pindado@upm.es; j.cubas@upm.es; felix.sorribes@upm.es

2 Departamento de Infraestructura, Sistemas Aeroespaciales y Aeropuertos, Universidad Politécnica de Madrid, ETSI Aeronáuticos, Pza. Del Cardenal Cisneros 3, Madrid 28040, Spain; E-Mail: spindado@aero.upm.es

* Author to whom correspondence should be addressed; E-Mail: santiago.pindado@ upm.es; Tel.: +34-913366353; Fax: +34-913366363.

\section{Published: 1 June 2014}

\begin{abstract}
The cup anemometer has been used widely by the wind energy industry since its early beginning, covering two fundamental aspects: wind mill performance control and wind energy production forecast. Furthermore, despite modern technological advances such as LIDAR and SODAR, the cup anemometer remains clearly the most used instrument by the wind energy industry. Together with the major advantages of this instrument (precision, robustness), some issues must be taken into account by scientists and researchers when using it. Overspeeding, interaction with stream wakes due to allocation on masts and wind-mills, loss of performance due to wear and tear, change of performance due to different climatic conditions, checking of the maintenance status and recalibration, etc. In the present work a review of the research campaigns carried out at the IDR/UPM Institute to analyze cup anemometer performance is included. Several aspects of this instrument are examined: the calibration process, the loss of performances due to aging and wear and tear, the effect of changes of air density, the rotor aerodynamics, and the harmonic terms contained in the anemometer output signal and their possible relation to the anemometer performances.
\end{abstract}

Keywords: cup anemometer; AEP; rotor dynamics; calibration; anemometer performance 


\section{Introduction}

At present, the use of wind speed anemometers (cup, propeller or sonic anemometers) is very common, their applications having spread from sectors such as meteorology or wind energy to others where the effect of the wind should be taken into account (moving bridges in civil engineering, big cranes, etc.). Nevertheless, the wind energy industry still can be considered as the biggest consumer of anemometers all over the world. Leaving aside the importance of having the most accurate instruments (as the wind power is proportional to the third power of the wind speed), the wind energy sector is extremely concerned with two aspects that, despite technological advances such as LIDAR and SODAR, require the use of anemometers: wind energy production forecast on the field, and wind turbine performance control. Within the past decades the wind energy sector has been openly supported by governments (Germany, Denmark, Spain...), concerned about clean energies and a reduction of their dependence on fossil fuels. In addition, new strong players in this industry like China, U.S.A., Brazil or India are now being very active, with large figures in terms of installed wind power and growing rates (see Figure 1). According to these facts it seems reasonable to assume that the mentioned massive demand of anemometers from this sector will be maintained in the incoming years, if not increased.

Figure 1. Installed wind power per country from 2005 to 2013. The graph includes data from some of the biggest producers in the world.

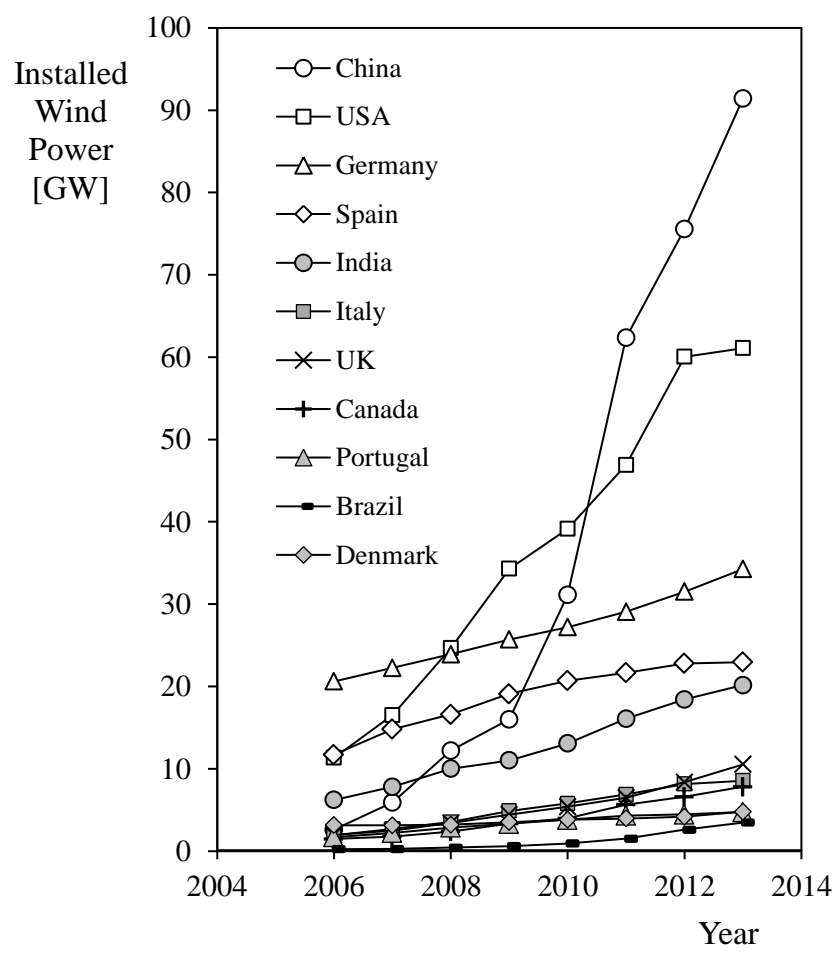

Among the different instruments devoted to measure the wind speed, the cup anemometer remains today the most used in the wind energy sector, as it is inexpensive when compared to other devices (e.g., sonic anemometers), shows linear response in the normal wind speed range (according to MEASNET procedures, anemometer calibration wind speed ranges between $4 \mathrm{~m} \mathrm{~s}^{-1}$ and $16 \mathrm{~m} \mathrm{~s}^{-1}$ ), and is capable to operate in quite extreme weather conditions. The behavior of this meteorological 
instrument has been widely studied along the twentieth century. Early studies focused on the optimal number of cups and arm length, cup aerodynamics, frequency recording system design, and errors due to fluctuating winds. Following those initial efforts, researchers focused on cup anemometer response in turbulent flows, as the accuracy of wind speed measurements became increasingly important. In addition, the importance of accuracy in wind speed measurements and the impracticality of constant recalibrations to maintain anemometer performance led researchers to study other aspects related to cup anemometer calibration. These include the impact of environmental (climatic) conditions, anemometer aging, the possibility of field calibration, the effects of wind stream non-uniformities, stream blockage and anemometer mounting arrangement on the calibration results, and uncertainties during the calibration processes. Finally, recent efforts have been made to classify the different anemometers available on the market, and to compare their performance as a function of their shape.

Figure 2. Left: Results from two calibrations performed at the IDR/UPM Institute, on the same cup anemometer (Thies Clima 4.3350) following two different procedures, AC and AD. AC calibrations follow strictly MEASNET procedure (wind speeds ranging from $4 \mathrm{~m} \mathrm{~s}^{-1}$ to $16 \mathrm{~m} \mathrm{~s}^{-1}$, and 13 measurement points are taken), whereas AD calibrations are carried out over a broader wind speed range (from $4 \mathrm{~m} \mathrm{~s}^{-1}$ to $23 \mathrm{~m} \mathrm{~s}^{-1}$ ) and less measurement points are taken (9 instead of 13). The transfer function resulting from the linear fitting to AC calibration data has been included in the graph, together with the coefficient of determination, $R^{2}$. Right: Cup anemometer equipped with a prototype rotor during calibration procedure at the S4 wind tunnel at the IDR/UPM Institute.
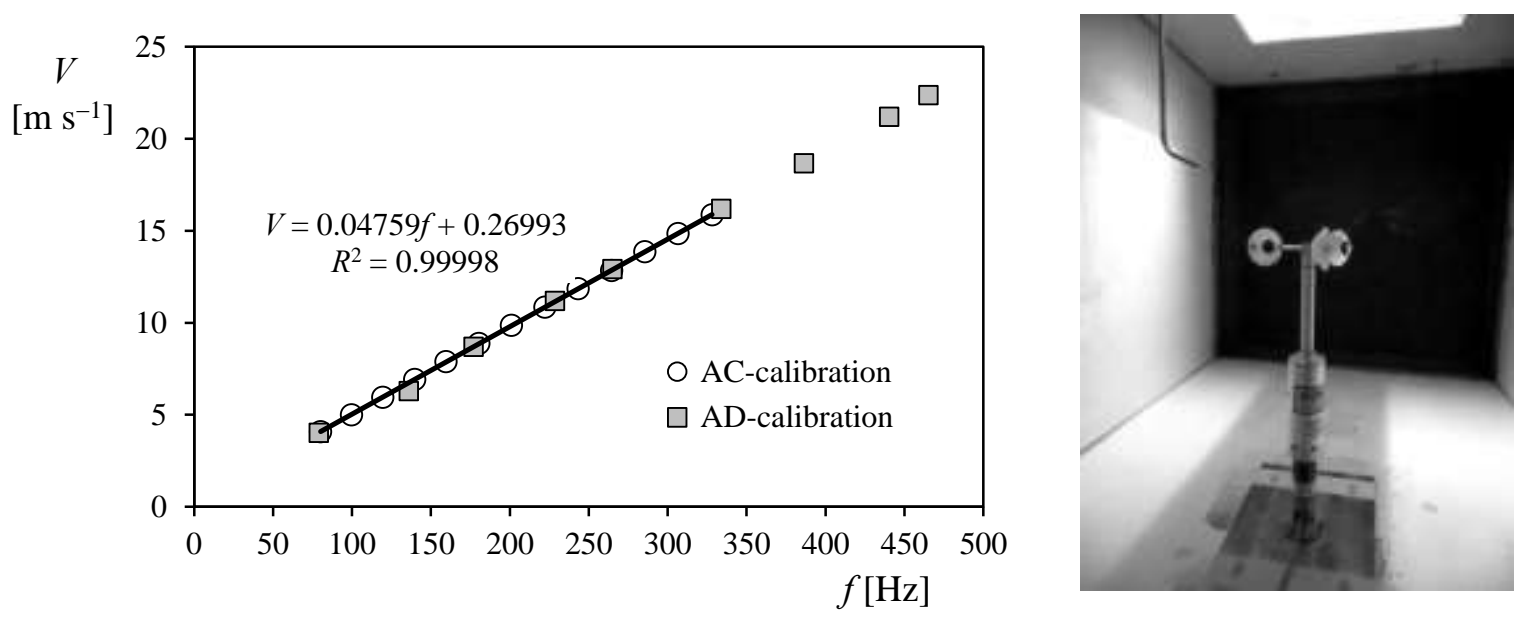

\section{The Calibration Process}

If, as said, the cup anemometer shows a linear behavior, then, the transfer function which relates the wind speed, $V$, to the output frequency of the anemometer, $f$, can obviously be expressed by a linear equation:

$$
V=\mathrm{A} \cdot f+\mathrm{B}
$$

where A (slope) and B (offset) are calibration coefficients defined by means of a calibration process in a wind tunnel (see Figure 2). Looking for a expression with a clearer physical meaning, the transfer 
function can be rewritten in terms of the anemometer's rotation frequency, $f_{r}$, instead of the output frequency, $f$ :

$$
V=\mathrm{A}_{r} \cdot f_{r}+\mathrm{B},
$$

where $\mathrm{A}_{r}$ is the result of multiplying calibration constant $\mathrm{A}$ by the number of pulses per revolution given by the anemometer, $N_{p}$. The number of pulses is different depending on the anemometer's inner system for translating the rotation into electric pulses. Magnet-based systems give 1 to 3 pulses per revolution, whereas optoelectronics-based systems normally give higher pulse rates per revolution, from 6 to 44. Finally, going back to the linearity of the cup anemometer performance on the aforementioned wind speed range, some authors claim that a non-linear expression should be used as the anemometer's transfer function instead of a linear one, especially at low wind speeds. Nevertheless, it should also be said that the linear expression is used as, in normal working conditions, it is accurate enough and recommended in standard calibration processes. In Table 1 some average values of the calibration coefficients corresponding to commercial anemometers calibrated at the IDR/UPM Institute are included.

\section{Analytical Models to Study Cup Anemometer Performance}

To analyze the behavior of cup anemometer, analytical models have been proposed by other authors in the past. These models are developed from the following expression:

$$
I \frac{\mathrm{d} \omega}{\mathrm{d} t}=Q_{A}+Q_{\mathrm{f}}
$$

where $I$ is the moment of inertia of the rotor, $Q_{A}$ is the aerodynamic torque, and $Q_{\mathrm{f}}$ is the frictional torque that depends on the air temperature, $T$, and the rotation speed, $\omega\left(Q_{\mathrm{f}}=B_{0}(T)+B_{1}(T) \omega+\right.$ $B_{2}(T) \omega^{2}$, where coefficients $B_{0}, B_{1}$, and $B_{2}$ are negative). The frictional torque, $Q_{\mathrm{f}}$, can be neglected as it is normally very small in comparison to the aerodynamic torque. The aerodynamic torque, $Q_{A}$, can be derived from the aerodynamic forces on the rotor cups, which are normally measured in a wind tunnel in "static" configuration, that is, measuring the forces on an isolated and fixed cup immersed in a constant wind speed air flow and without considering any rotational speed. The aerodynamic torque due to one single cup is expressed as a function of the aerodynamic normal-to-the-cup force coefficient measured in a wind tunnel, $c_{N}$, the wind speed, $V$, the rotation speed, $\omega$, the cup radius, $R_{c}$, the cup center rotation radius, $R_{r c}$, and the air density, $\rho$. Analytical models have proven to be a useful tool to study the cup anemometers performance, even in not fully functional conditions. Besides, the relationship between the performance of a cup anemometer and its shape has also been experimentally studied, mainly through measurements of the aerodynamic normal-force coefficients on the cups, $c_{N}$, as Breevort \& Joyner did in the past. Using those cup force coefficients as a function of the wind angle, some authors such as Schrenk, Wyngaard, Ramachandran, and Kondo derived different analytical models to study cup anemometer behavior. Both analytical and experimental research on cup anemometer behavior has shown the correlation between anemometer transfer functions and cup center rotation radius, $R_{r c}$. However, some differences have also been highlighted between the results obtained using the two methods, see Figure 3. 
Table 1. Mean and standard deviation values of calibration coefficients, A and B (1), of different commercial anemometers calibrated using MEASNET procedure at the IDR/UPM Institute. The coefficient of determination, $R^{2}$, related to the calibration linear fittings have been also included in the table. The values refer to new, not used, anemometers.

\begin{tabular}{|l|r|r|r|r|r|c|}
\hline \multicolumn{1}{|c|}{ Anemometer } & $\begin{array}{c}\text { Calibrations } \\
\text { averaged }\end{array}$ & $\begin{array}{c}\text { A } \\
\text { mean }\end{array}$ & $\begin{array}{c}\boldsymbol{\sigma}_{\mathrm{A}} \\
{\left[\mathbf{x 1 0}^{4}\right]}\end{array}$ & $\begin{array}{c}\text { B } \\
\text { mean }\end{array}$ & $\begin{array}{c}\boldsymbol{\sigma}_{\mathrm{B}} \\
{\left[\mathbf{x 1 0}^{2}\right]}\end{array}$ & $\begin{array}{c}\boldsymbol{R}^{2} \\
\text { mean }\end{array}$ \\
\hline RISØ P2546A & 83 & 0.627 & 33.17 & 0.179 & 1.77 & 0.99999 \\
\hline Thies 4.3350 & 874 & 0.0483 & 1.93 & 0.248 & 2.47 & 0.99999 \\
\hline Thies 4.3351 & 115 & 0.0460 & 1.44 & 0.267 & 2.71 & 0.99999 \\
\hline Climatronics 100075 & 35 & 0.0473 & 3.06 & 0.208 & 2.85 & 0.99997 \\
\hline Vector Inst. A100 L2 & 189 & 0.0505 & 3.27 & 0.184 & 2.86 & 0.99998 \\
\hline Ornytion 107 & 77 & 0.624 & 47.01 & 0.215 & 2.48 & 0.99998 \\
\hline Vaisala WAA 151 & 4 & 0.0995 & 3.88 & 0.305 & 3.71 & 0.99998 \\
\hline Vaisala WAA 252 & 9 & 0.104 & 10.13 & 0.213 & 2.33 & 0.99998 \\
\hline
\end{tabular}

Figure 3. Cup anemometer factor, $K$ (defined as $K=U_{\infty} / 2 \pi f_{r} R_{r c}$, where $U_{\infty}$ is the wind speed, $f_{r}$ is the anemometer's rotation frequency, and $R_{r c}$ is the cups center rotation radius), as a function of the ratio between the cups radius, $R_{c}$, and the cups center rotation radius, $R_{r c}$ (see geometry sketch on the right side). The experimental results (white circles) measured with a Climatronics 100075 ane mometer equipped with conical cups rotors. These rotors were built with the same cup radius, $R_{c}=30 \mathrm{~mm}$, and varying the cups center rotation radius, $R_{r c}$. The linear fitting to these testing results has been added as a dashed line. The results from several commercial anemometers have been added to the graph, together with the analytical result calculated for the corresponding conical cups.
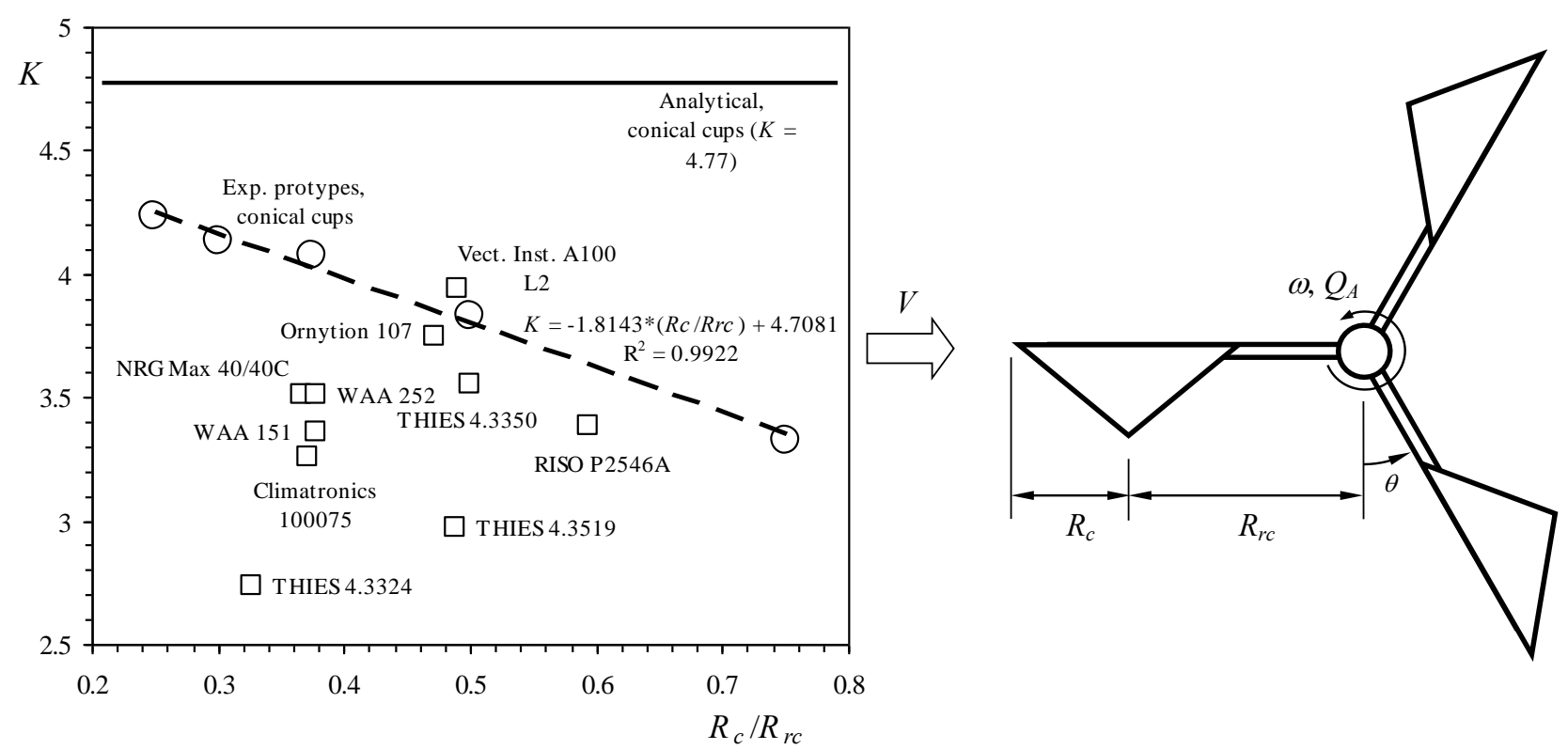

\section{Influence of Air Density, Ageing, and Damage Condition on the Cup Anemometer Performance}

The effect of density was analyzed in a previous campaign. The effect of density changes in relation to the calibration transfer function constants A and B were observed. Large series of calibrations were 
analyzed and, as a result, the general trend obtained with calibrations performed on different anemometers of the same type, was found to be quite similar to the behavior shown by a single anemometer (estimated by multiple calibrations). In addition, the ageing was also studied in a specific research carried out at the IDR/UPM Institute. Two different analyses were done, the first concerns three specific cup anemometers used at the IDR/UPM calibration laboratory for internal procedures, the second one is related to some cup anemometers that were sent several times to the IDR/UPM, to be calibrated in each occasion after a period in service. The results showed a different degradation pattern for different cup anemometers. Besides, a greater scattering, regarding the loss of performance level, were showed within the first 300 days in service than the one showed in the period between 300 and 600 days. This result seems to indicate a greater level of degradation of the cup anemometer in the first year of service. The problem of the cup anemometer maintenance and condition monitoring has been recently studied using Fourier analysis of the output signal. The results are very promising as degradation of the rotor geometry has been observed using this analysis, the experimental data being also correlated with analytical models.

\section{Conclusions}

The cup anemometer is at present the best option for wind speed measurements regarding the specific applications for the wind energy industry [1] (e.g., wind energy production analysis at specific locations, or wind mill performance control).

Research carried out in the past years at the IDR/UPM Institute indicate that there is still possibilities to optimize the aerodynamics of this mechanical sensor [2-4] and, even more promising for the industry, a new way to monitor the sensor status based on the anemometer output signal processing is being developed [3].

\section{References}

1. International Electrotechnical Commision International Standard IEC-61400-12-1. Wind Turbines. Part 12-1: Power performance measurements of electric ity producing wind turbines. First edition, 2005-12 2005.

2. Pindado, S.; Sanz-Andrés, A.; Sorribes, F. Mathematical analysis of the effect of the rotor geometry on cup anemometer response. Accept. Publ. Sci. World J. 2014.

3. Pindado, S.; Cubas, J.; Sanz-Andrés, A. Aerodynamic analysis of cup anemometers performance. The stationary harmonic response. Sci. World J. 2013, 2013, 1-11.

4. Pindado, S.; Pérez, J.; Avila-Sanchez, S. On cup anemometer rotor aerodynamics. Sensors (Basel). 2012, 12, 6198-6217.

(C) 2014 by the authors; licensee MDPI, Basel, Switzerland. This article is an open access article distributed under the terms and conditions of the Creative Commons Attribution license (http://creativecommons.org/licenses/by/3.0/). 